\title{
REVIEWS
}

\section{Aborted sudden cardiac death: a clinical perspective}

\author{
P Mazeika
}

\begin{abstract}
Sudden cardiac death in the community remains a major public health problem. The purpose of this article is to outline the epidemiology, pathophysiology, and immediate treatment of the cardiac arrest victim. The subsequent in-hospital diagnostic evaluation and management will then be discussed with an emphasis on the role of the implantable cardioverterdefibrillator. A systematic and evidence based approach should help to optimize patient care.

(Postgrad Med f 2001;77:363-370)
\end{abstract}

Keywords: cardiology; implantable cardioverterdefibrillator; resuscitation; sudden cardiac death

\section{Epidemiology}

Sudden cardiac death is defined as unexpected natural death due to cardiac causes, heralded by abrupt loss of consciousness, and occurring within one hour of the onset of acute symptoms. ${ }^{1}$ It is estimated that approximately 300000 cases of sudden cardiac death occur per year in the United States with about 50000 cases per year in the United Kingdom. ${ }^{2}$ However, the nature of the condition makes estimates of incidence speculative. Around $80 \%$ of sudden cardiac deaths occur in the home, $40 \%$ are unwitnessed, and bystander cardiopulmonary resuscitation is initiated in only $10 \%-20 \%$ of cases. ${ }^{3}$

Because up to $80 \%$ of cardiac arrest survivors have coronary artery disease, the epidemiology of these two conditions run parallel. ${ }^{4}$ Some autopsy series have documented significant coronary atherosclerosis in over $90 \%$ of victims. ${ }^{5}$ This may be because patients with non-coronary pathology are more likely to survive cardiac arrest.

The annual risk of sudden cardiac death for the whole population is about $0.1 \%,{ }^{3}$ rising to an estimated $2 \%-4 \%$ for patients with hypertrophic cardiomyopathy, idiopathic dilated cardiomyopathy, or arrhythmogenic right ventricular dysplasia, and to around $20 \%$ for cardiac arrest survivors in the era before availability of the implantable cardioverterdefibrillator (ICD). ${ }^{6}$

\section{Underlying pathology}

Table 1 outlines common and important conditions found in these patients. Major predisposing pathological substrates include the presence of a myocardial scar, ventricular hypertrophy from any cause, the various types of cardiomyopathy, and a primary electrical abnormality. About $80 \%$ of cardiac arrest survivors have coronary atherosclerosis, $15 \%$ have non-coronary structural heart disease, and the remaining $5 \%$ have no identifiable structural substrate.

Hypertrophic cardiomyopathy is the commonest cause of sudden cardiac death in athletes aged less than 35 years whereas in older age groups coronary artery disease is the predominant aetiology. Concussion of the heart from non-penetrating blunt trauma to the anterior chest (commotio cordis) is a recognised cause of sudden death during sporting activities and is seen particularly in the young because of the presence of a more compliant chest wall.

Drugs are an important preventable cause of sudden cardiac death. The Cardiac Arrhythmia Suppression Trial (CAST) served to highlight the dangerous proarrhythmic potential of antiarrhythmic drugs in patients with underlying structural heart disease. ${ }^{8}$ Diuretics have been incriminated as a cause of cardiac arrest in the hypertensive patient. ${ }^{9}$ This may be mediated by hypokalaemia or hypomagnesaemia.

In about $5 \%$ of victims of sudden death, no evidence of structural heart disease can be found. The Unexplained Cardiac Arrest Registry of Europe (UCARE) and the Idiopathic

Table 1 Causes and contributory factors in sudden cardiac death

\begin{tabular}{|c|c|}
\hline Condition & Examples \\
\hline Coronary atherosclerosis & Remote myocardial infarction, acute myocardial infarction, acute myocardial ischaemia, left ventricular aneurysm \\
\hline Cardiomyopathy & Hypertrophic cardiomyopathy, dilated cardiomyopathy, arrhythmogenic right ventricular dysplasia, cardiac sarcoid, myocarditis \\
\hline Valvular heart disease & Aortic stenosis, prosthetic valve dysfunction \\
\hline Congenital heart disease & $\begin{array}{l}\text { Eisenmenger's syndrome, tetralogy of Fallot, transposition of the great arteries, pulmonary vascular obstruction, congenital } \\
\text { coronary artery anomaly }\end{array}$ \\
\hline Electrophysiological abnormality & $\begin{array}{l}\text { Wolff-Parkinson-White syndrome, conduction system disease, congenital long QT syndrome, idiopathic ventricular fibrillation, } \\
\text { Brugada syndrome }\end{array}$ \\
\hline Miscellaneous & $\begin{array}{l}\text { Coronary artery spasm, Marfan's syndrome, pulmonary hypertension, drugs (non-cardiac, cardiac, antiarrhythmic, illicit), } \\
\text { ruptured sinus of valsalva aneurysm }\end{array}$ \\
\hline
\end{tabular}




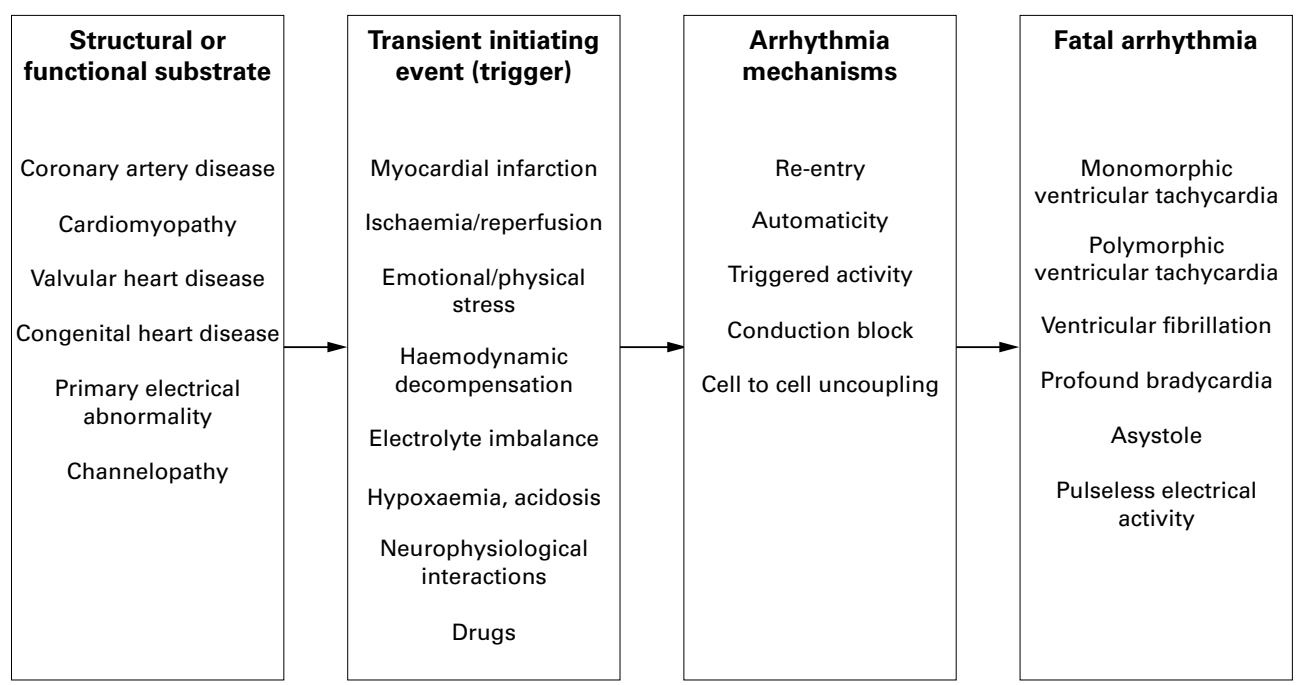

Figure 1 Simplified conceptual framework to aid understanding of the pathophysiology of sudden cardiac death.

Ventricular Fibrillation registry of the United States (IVF-US) have recently been established to gather more information on these cases. ${ }^{10}{ }^{11}$

Pathophysiology of sudden cardiac death The mechanisms triggering fatal arrhythmias are complex and poorly understood but are likely to vary depending on the underlying pathology and probably also between patients with the same pathology (fig 1).

Plaque rupture with superadded thrombus in the coronary tree are found at necropsy in many sudden cardiac death victims with coronary atherosclerosis and suggests a role for myocardial ischaemia as an initiator of the terminal event. However, only about $20 \%$ of cardiac arrest survivors have features of acute transmural myocardial infarction, although approximately half have evidence of remote myocardial infarction with a healed scar. ${ }^{12}$ Small cardiac enzyme elevations are the rule and likely reflect a combination of factors including non-Q wave myocardial infarction, transient circulatory failure, cardiopulmonary resuscitation, and defibrillation.

Clearly, plaque vulnerability, electrical instability, and thrombotic tendency are key pathophysiological issues in the coronary patient. Experimental studies in animals with healed infarcts have confirmed that superadded ischaemia in this setting is particularly likely to provoke malignant ventricular arrhythmias. In the clinical arena, vigorous unaccustomed exercise and profound emotional or psychological stress are well recognised precipitants of

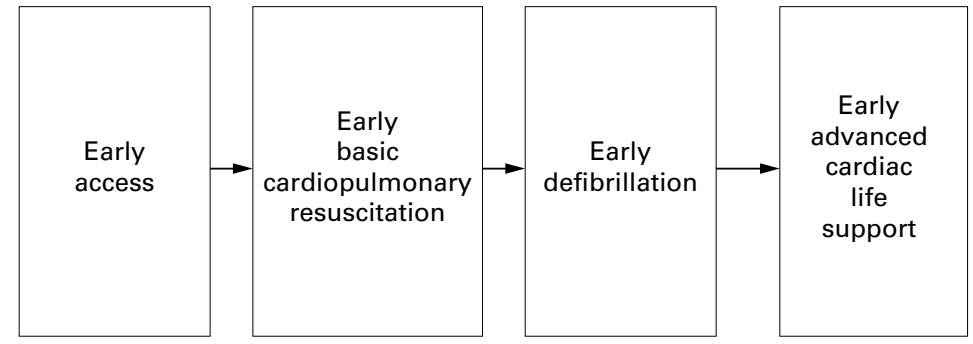

Figure 2 The chain of survival. sudden cardiac death in people with established coronary atherosclerosis. Rarely, a supraventricular arrhythmia can precipitate sudden death. ${ }^{13}$

\section{Resuscitation in the community}

The key elements of a community resuscitation programme, represented in the "chain of survival" motif, are early access, early basic cardiopulmonary resuscitation, early defibrillation, and early advanced cardiac life support (fig 2). ${ }^{14}$ Victims of cardiac arrest in the community tend to have less comorbidity and fewer systemic precipitants than patients who arrest in hospital. ${ }^{15}$

Bottiger et al reported long term outcome after out of hospital cardiac arrest with a physician staffed emergency response system serving an urban/suburban area of 330000 inhabitants. ${ }^{16}$ For 338 patients, return of spontaneous circulation was seen in $49 \%$, survival to intensive care unit admission in $38 \%$, and survival to hospital discharge and one year was achieved in $14 \%$ and $12 \%$ of patients, respectively. Overall, five lives were saved per 100000 population per year.

\section{Early in-hospital management}

As full recovery after cardiac arrest is rarely immediate, restoration of sinus rhythm marks the start and not the end of a resuscitation attempt. Without treatment, irreversible cerebral dysfunction occurs within about three minutes of circulatory arrest.

Meticulous control of blood gases, $\mathrm{pH}$, and electrolytes in the period immediately after the arrest is necessary. In many cases, this can be achieved only by endotracheal intubation and mechanical ventilation of a sedated and paralysed patient on the intensive care unit. The haemodynamics of the period after cardiac arrest are complex and generally require invasive monitoring of arterial, central venous, and pulmonary capillary wedge pressure as well as cardiac output. Myocardial dysfunction with haemodynamic instability is the rule. The maintenance of an adequate cerebral perfusion 
Table 2 Selected causes of sudden cardiac death and elements of their diagnostic work-up

\begin{tabular}{ll}
\hline Condition & Investigation \\
\hline Coronary artery disease & Coronary angiography, stress testing \\
Coronary artery spasm & Ergonovine study \\
Myocarditis; sarcoidosis & Endomyocardial biopsy \\
Hypertrophic and dilated cardiomyopathy; aortic stenosis & Echocardiography \\
Arrhythmogenic right ventricular dysplasia & Magnetic resonance imaging, signal averaged electrocardiogram \\
Wolff-Parkinson-White syndrome; supraventricular tachycardia & Electrophysiological testing \\
Brugada syndrome & Pharmacological challenge with a sodium channel blocker \\
Congenital long QT syndrome; hypertrophic cardiomyopathy; Brugada syndrome & Family screening, genotyping \\
Illicit drug abuse & Blood and urine toxicology screen \\
\hline
\end{tabular}

pressure, by ensuring an optimal mean arterial pressure, may be aided by a low to normal carbon dioxide partial pressure, to minimise cerebral oedema. Close monitoring of haemodynamics and urine output can be used to guide fluid management and circulatory support with inotropes, vasodilators and, if necessary, the intra-aortic balloon pump. Cardiac arrhythmias are extremely common and recurrent ventricular fibrillation is seen in $10 \%-20 \%$ of patients, usually within the first 48 hours of hospitalisation. Persistent ventricular arrhythmias may be managed with intravenous lignocaine (lidocaine) or amiodarone.

Where arrest complicates acute myocardial infarction, decisions regarding acute percutaneous coronary intervention or coronary thrombolysis should be made on an individual patient basis, carefully weighing the risks versus benefits. Restoration of vessel patency at the time of acute infarction may reduce the occurrence of subsequent ventricular arrhythmias. ${ }^{17}$ These patients should be managed like any other acute myocardial infarct.

Common respiratory problems in these patients include the adult respiratory distress syndrome, aspiration, pneumothorax, and rib fractures. Some degree of aspiration is probably an inevitable consequence of cardiopulmonary resuscitation. Gastric decompression with a nasogastric tube and prophylactic antibiotics should be considered. Seizures secondary to anoxic encephalopathy occur frequently and may require anticonvulsants. Residual permanent cognitive impairment is seen in a significant minority of cardiac arrest survivors. As in all critically ill patients, the risk of stress ulceration should be countered with appropriate medications such as ranitidine or sucralfate.

Unfortunately, many patients who are initially resuscitated die within 72 hours from persistent cerebral or myocardial dysfunction after arrest. However, in the period immediately after resuscitation it is not possible to reliably predict long term outcome and therefore all patients should be managed aggressively. In patients who are unconscious when admitted to hospital, the prognosis becomes more unfavourable the longer coma persists. In one study, $25 \%$ of patients who regained consciousness did so by the time of admission, $71 \%$ by day 1 , $86 \%$ by day 2 , and $92 \%$ by day $3 .{ }^{18}$ The usual practice is to provide full support in the intensive care unit for at least 72 hours. A persistent vegetative state may develop in a small minority of survivors. ${ }^{19} 20$

\section{Diagnostic evaluation}

Survivors of out of hospital cardiac arrest not associated with acute transmural myocardial infarction who are neurologically intact require an extensive diagnostic work-up. Two key issues are the diagnosis of the underlying substrate and the identification of reversible causes of cardiac arrest (table 2). The strong link between coronary artery disease and sudden cardiac death makes coronary angiography, stress testing, and assessment of left ventricular function essential and helps determine the need for coronary revascularisation. Left ventricular function is commonly abnormal, often severely so, and is the most important determinant of long term outcome in these patients. ${ }^{21}$ Among the cardiomyopathies, arrhythmogenic right ventricular dysplasia is an uncommon but important cause of malignant ventricular arrhythmias. The diagnostic criteria for this condition have recently been reported..$^{22}$

It has been estimated that a precipitant of the arrhythmia can be identified in $25 \%$ of cases with no obvious trigger in the other $75 \%$. This issue influences the risk of recurrence. Recognised factors include acute myocardial infarction and ischaemia, severe hypokalaemia, supraventricular tachycardia, and drug proarrhythmia.

Acute $\mathrm{Q}$ wave myocardial infarction is seen in about $20 \%$ of patients who have coronary atherosclerosis as the underlying pathology. Moderate cardiac enzyme elevations compatible with periarrest non-Q wave myocardial infarction are very common but may also be due to transient circulatory arrest, cardiopulmonary resuscitation, and defibrillation. As it is generally not possible to make the distinction with certainty, these findings do not preclude recommendation of an ICD.

Acute myocardial ischaemia can precipitate ventricular fibrillation. These patients give a history of angina before collapse and usually have angiographic evidence of severe coronary artery disease with physiological data confirming reversible ischaemia. The diagnosis is more secure if there is no wall motion abnormality and left ventricular function is normal.

Severe hypokalaemia (potassium $<2.5$ $\mathrm{mmol} / \mathrm{l}$ ), often related to diuretic use, can trigger a fatal ventricular arrhythmia. However, in the period after resuscitation, hypokalaemia may be due to the effects of catecholamine release and therefore can be a consequence rather than a cause of the cardiac arrest.

Ventricular arrhythmias secondary to various medications, antiarrhythmic agents, and illicit drugs such as cocaine are an important 


$\begin{array}{lccc}\begin{array}{c}\text { Aetiology } \\ \text { Treatment }\end{array} & \begin{array}{c}\text { Reversible } \\ \text { Correct reversible } \\ \text { factors }\end{array} & \begin{array}{c}\text { Correct reversible } \\ \text { factors + ICD }\end{array} & \text { ICD } \\ \text { CAD } & \begin{array}{c}\text { Myocardial ischaemia } \\ \text { No previous MI }\end{array} & \begin{array}{c}\text { Myocardial ischaemia } \\ \text { Previous MI }\end{array} & \text { No myocardial ischaemia } \\ \text { Treatment } & \begin{array}{c}\text { Cormal LV function } \\ \text { Conary }\end{array} & \begin{array}{c}\text { Impaired LV function } \\ \text { revascularisation }\end{array} & \text { Impaired LV function } \\ & \text { revascularisation + ICD } & \text { ICD }\end{array}$

Figure 3 Management of the cardiac arrest survivor (CAD, coronary artery disease; ICD, implantable cardioverter-defibrillator; LV, left ventricular; MI, myocardial infarction).

preventable cause of cardiac arrest. Class Ia and class III agents as well as many non-cardiac medications, such as antihistamines, antidepressants, and major tranquillisers can prolong the QT interval and cause torsade de pointes tachycardia by generating early afterdepolarisations.

\section{General aspects of management}

As approximately $80 \%$ of cardiac arrest survivors have coronary atherosclerosis, it is imperative that all coronary risk factors such as hypertension, hypercholesterolaemia, cigarette smoking, diabetes, and obesity are managed aggressively. Regular exercise on a cardiac rehabilitation programme may, by increasing vagal tone, be protective. Anxiety and depression are not uncommon and require early recognition, counselling, and psychological support. ${ }^{23}$

For patients with coronary atherosclerosis, aspirin $75-325 \mathrm{mg} /$ day should be prescribed indefinitely, unless contraindicated. A recent overview of 145 randomised trials of prolonged antiplatelet treatment versus control in about 70000 patients concluded that in a wide range of patients at high risk of occlusive vascular disease aspirin offers worthwhile protection against myocardial infarction, stroke, and death. $^{24}$

Lipid lowering treatment with a hydroxymethyglutaryl coenzyme A reductase inhibitor has been shown to reduce total mortality in patients with coronary artery disease in several clinical trials. For example, the Scandinavian Simvastatin Survival Study (4S) showed that simvastatin significantly improved survival and reduced the occurrence of major coronary events and need for myocardial revascularisation in patients with angina pectoris or previous myocardial infarction with a raised serum cholesterol despite dietary measures. ${ }^{25}$

Cardiac arrest survivors with congestive heart failure should be treated with an angiotensin converting enzyme (ACE) inhibitor as there is overwhelming evidence that they confer prognostic benefit. ${ }^{26}$ Clinical trials in patients after infarct have also shown that these drugs reduce mortality. A recent meta-analysis of 15 clinical trials involving over 15000 patients found that ACE inhibitor treatment significantly reduced total mortality, cardiovascular death, and sudden cardiac death in patients after recent myocardial infarction. ${ }^{27}$ Where ACE inhibitors are not tolerated or contraindicated, alternatives include nitrates plus hydralazine and treatment with a specific angiotensin II receptor blocker such as losartan. ${ }^{28}$

The Randomized Aldactone Evaluation Study (RALES) found that spironolactone, an aldosterone receptor blocker, substantially reduces the risk of both morbidity and death among patients with severe heart failure. ${ }^{29}$ Spironolactone $25-50 \mathrm{mg}$ per day or placebo was added to conventional treatment with an ACE inhibitor, loop diuretic and digoxin, and after a mean follow up of 24 months, total mortality was reduced from $46 \%$ in the placebo group to $35 \%$ in the spironolactone group $(p<0.001)$. Sudden death was also reduced $(p=0.02)$ and the authors speculated that these beneficial effects might arise by the avoidance of potassium loss or the prevention of myocardial fibrosis.

The value of $\beta$-blockade in patients after myocardial infarction is well established. ${ }^{30}$ More recently, treatment with $\beta$-blockers in patients with chronic stable heart failure has been shown to reduce all-cause mortality and prevent sudden death in three prospective randomised trials. These were the US Carvedilol Heart Failure Study, ${ }^{31}$ the Metoprolol CR/XL Randomized Intervention Trial in Congestive Heart Failure (MERIT-HF), ${ }^{32}$ and the Cardiac Insufficiency Bisoprolol Study II (CIBIS II). ${ }^{33}$ The addition of carvedilol (3.125-50 mg twice a day), controlled release metoprolol (12.5$200 \mathrm{mg}$ once a day), or bisoprolol (1.25-10 mg once a day) to conventional treatment was effective and well tolerated. These studies included patients with both ischaemic and non-ischaemic heart failure in functional class $2-4$ and raise the possibility that $\beta$-blockade may prevent sudden death by an antifibrillatory effect.

Although there is no direct evidence that any of the drugs outlined above are of value in the cardiac arrest survivor, their benefits are likely to extend to most of these patients.

\section{Coronary revascularisation}

Cardiac arrest in patients with coronary atherosclerosis occurs in three overlapping settings: acute myocardial infarction; transient myocardial ischaemia without infarction; and ventricular arrhythmias arising from a previous, healed, myocardial infarct (fig 3).

A small group of patients have myocardial ischaemia as the primary cause of cardiac arrest. Collapse typically occurs in relation to exercise, there is an antecedent history of chest pain but no evidence of acute infarction and subsequent stress testing reveals severe ischaemia with a large amount of jeopardised myocardium. Cardiac catheterisation shows severe proximal multivessel disease and normal global left ventricular systolic function with no evidence of a regional wall motion abnormality. Most experts agree that these patients can be managed with coronary revascularisation alone without cardioverter-defibrillator implantation, with decisions between coronary artery 
Table 3 Implantable cardioverter defibrillator (ICD) secondary prevention trials

\begin{tabular}{llll}
\hline & AVID & CIDS & CASH \\
\hline No of patients & 1016 & 659 & 349 \\
No of patients with ventricular fibrillation (\%) & $455(45)$ & $35(48)$ & $?$ \\
Mean patient age (years) & 65 & 63 & $\sim 57$ \\
Per cent with CAD & 81 & 82 & $\sim 80$ \\
Mean left ventricular ejection fraction (\%) & 32 & 34 & $\sim 40$ \\
Antiarrhythmic drug group treatment & Amiodarone, sotalol & Amiodarone & Amiodarone, metoprolol \\
Mean follow up (months) & 18.2 & 35.4 & 24 \\
Primary endpoint & Total mortality & Total mortality & Total mortality \\
Two year total mortality in ICD group (\%) & 18 & 15 & 12 \\
Two year total mortality in AAD group (\%) & 25 & 21 & 20 \\
p Value & $<0.02$ & 0.142 & 0.047 \\
\hline
\end{tabular}

AAD, antiarrhythmic drug; AVID, Antiarrhythmics Versus Implantable Defibrillators Study; CAD, coronary artery disease; CASH, Cardiac Arrest Study Hamburg; CIDS, Canadian Implantable Defibrillator Study.

bypass grafting and percutaneous coronary intervention being made on an individual case basis.

At the other end of the clinical spectrum are patients with previous myocardial infarction who collapse while resting and give no history of preceding chest pain or limiting angina. Stress testing typically reveals minimal or no reversible ischaemia. Cardiac catheterisation shows non-critical coronary artery disease and depressed global left ventricular function with a fixed wall motion abnormality. Implantation of a cardioverter-defibrillator without concomitant coronary revascularisation is appropriate. Many patients fall between these extremes and require both coronary revascularisation and an ICD. As the procedural risk of cardioverter-defibrillator implantation is higher in patients with untreated myocardial ischaemia, coronary revascularisation should be undertaken first.

Observational data from the Coronary Artery Surgery Study (CASS) registry supports this approach. ${ }^{34} \mathrm{~A}$ comparison of medical with surgical treatment in 13476 patients using multivariate techniques found that coronary artery bypass grafting significantly reduced the incidence of sudden cardiac death and total mortality over five years of follow up. The relief of myocardial ischaemia may have reduced or eliminated the events triggering malignant ventricular arrhythmias in these patients. Similar positive findings were reported from Seattle by Every et al in 265 survivors of out of hospital cardiac arrest resuscitated between 1970 and $1988 .^{35}$

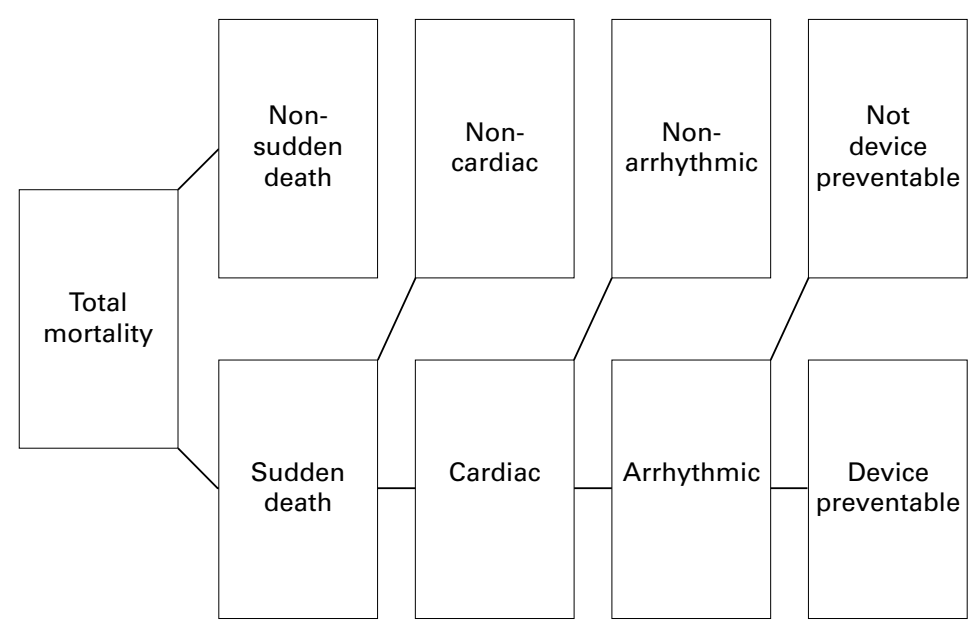

Figure 4 What proportion of total mortality is device preventable?
The implantable cardioverter-defibrillator

Implantation of a cardioverter-defibrillator is the most important element of treatment for the cardiac arrest survivor and has been shown to improve survival in several clinical trials (table 3). The Antiarrhythmics Versus Implantable Defibrillator (AVID) study observed clinical benefit from ICD therapy only in patients with a left ventricular ejection fraction $<35 \% .^{36}$ Furthermore, the average unadjusted length of additional life associated with ICD therapy in AVID was only 2.7 months after three years of follow up raising the issue of competing causes of death and what proportion of total mortality is device preventable in these patients (fig 4). The Cardiac Arrest Study Hamburg (CASH) trial also had a propafenone group which was discontinued early after a significant excess mortality was observed. ${ }^{47}$ It is possible that the smaller ICD benefit found in the Canadian Implantable Defibrillator Study (CIDS) was due to its longer duration of follow up compared with AVID as the two studies were of similar statistical power. ${ }^{38}$ One would expect deaths that were not device preventable to become more prominent with longer follow up.

Based on the above studies the American College of Cardiology/American Heart Association guidelines list cardiac arrest due to ventricular tachycardia or ventricular fibrillation without a transient or reversible cause as a class I indication for ICD therapy. ${ }^{39}$ Outcome data from the AVID registry which includes trial eligible randomised, eligible nonrandomised, and ineligible patients has recently been reported. ${ }^{40} \mathrm{~A}$ surprise finding was that cardiac arrest survivors with or without an identifiable transient or correctable cause for the arrhythmia had a similarly poor prognosis: mortality was $18 \%$ compared with $17 \%$ during a mean follow up of 17 months. Clinical judgment regarding the presence of a reversible factor may be inaccurate raising the possibility that ICD therapy may be beneficial for a broader range of patients than previously thought, especially if the left ventricular ejection fraction is $<35 \%$.

Technological advances have greatly reduced the size of cardioverter-defibrillators such that transvenous prepectoral implantation under conscious sedation is now routine and has a mortality risk of less than $1 \%$. Current devices 
are multiprogrammable with extensive diagnostic features including event counters, episode logs, and stored electrograms, which are very helpful for troubleshooting.

Biphasic shocks result in a substantially lower defibrillation threshold and have therefore replaced the monophasic waveform. Bidirectional shock vectors involving two lead coils and the ICD casing offer advantages over conventional bipolar or single coil unipolar configurations and are in common use. Defibrillation thresholds around $10 \mathrm{~J}$ are usual and tend to be lower with device implantation on the left side. It may be appropriate to abbreviate defibrillation threshold testing in some patients with poor cardiac function to minimise procedural risk. Current systems use integrated bipolar sensing between the lead tip electrode and the large distal coil which theoretically makes oversensing more likely. Leads with true dedicated bipolar sensing may be superior but are difficult to manufacture and not yet generally available. Device testing at implant is done at the least sensitive setting. If sensing of ventricular fibrillation is adequate the device is generally programmed to a more sensitive level which provides a fourfold safety margin, making oversensing more likely in the long term. Similarly, when programming shock therapy in the ventricular fibrillation zone, the first shock administered should have a $10 \mathrm{~J}$ safety margin over the defibrillation threshold as this threshold rises by about $5 \mathrm{~J}$ in around $50 \%$ of patients over the ensuing months.

For most cardiac arrest survivors a single chamber ICD suffices. Detection enhancements such as stability algorithms, onset criteria, and arrhythmia duration have also helped to reduce the frequency of shocks triggered by sinus tachycardia, atrial fibrillation, or nonsustained ventricular tachycardia.

Devices can be configured to provide different therapies in different tachycardia cycle length zones. For rapid ventricular tachycardia or ventricular fibrillation, a high energy shock is appropriate first line treatment. Cardiac arrest survivors often experience sustained monomorphic ventricular tachycardia of intermediate cycle length which is pace terminable and therefore it is well worth adding a antitachycardia pacing zone. ${ }^{41}$

Defibrillator follow up is scheduled for every three months as a minimum and patients should be encouraged to carry personal identification and information about their device with them at all times. Patients should not drive for six months after implantation and for six months after each subsequent shock. Commercial driving should be prohibited indefinitely. ${ }^{42}$

\section{Other aspects of arrhythmia management}

Amiodarone is a potential alternative treatment if cardioverter-defibrillator implantation is contraindicated or refused. Contraindications include major cerebral dysfunction after arrest, significant psychiatric morbidity, terminal illness with life expectancy less than six months, and functional class 4 drug refractory heart failure in patients who are not candidates for cardiac transplantation. This drug has a complex pharmacological profile, multiple mechanisms of action, and the potential for serious side effects with long term treatment including pulmonary fibrosis, hepatic toxicity, and thyroid dysfunction. Close monitoring is therefore essential. Amiodarone has a half life of 30-100 days and therefore peak effect occurs only after several weeks of treatment with an oral loading dose.

The Cardiac Arrest in Seattle: Conventional versus Amiodarone Drug Evaluation (CASCADE) study compared empiric amiodarone to a Holter or electrophysiological study guided alternative antiarrhythmic agent (most commonly quinidine or procainamide) in 228 survivors of out of hospital ventricular fibrillation. ${ }^{43}$ Survival free of cardiac death, resuscitated ventricular fibrillation, or a syncopal defibrillator shock at two years was $82 \%$ for amiodarone compared with $69 \%$ for conventional treatment $(p=0.007)$. A recent metaanalysis of 15 randomised trials of amiodarone for the prevention of sudden cardiac death found that amiodarone significantly reduced total mortality by $10 \%$ (placebo controlled trial only) to $19 \%$ (all trials). ${ }^{44}$ Mortality reductions were similar in trials enrolling patients after myocardial infarction $(21 \%)$, with left ventricular dysfunction $(22 \%)$, and after cardiac arrest $(25 \%)$.

Approximately one third of cardioverterdefibrillator recipients also receive antiarrhythmic medication, most commonly for the control of coexisting supraventricular arrhythmias such as atrial fibrillation. Another important indication is frequent device discharges, which, if unchecked, can substantially reduce the ICD's usual five year longevity. Patient's presenting with multiple appropriate shocks are generally admitted to hospital and stabilised with intravenous lignocaine or procainamide. If recurrent ventricular tachycardia persists, intravenous or oral amiodarone combined with a $\beta$-blocker is usually effective. ${ }^{45}$ Sotalol (160-320 mg per day) has been shown to significantly reduce the probability of an appropriate first shock and also to prevent the occurrence of shocks for supraventricular arrhythmias in a double blind placebo controlled clinical trial. ${ }^{46}$

The possibility of an adverse drug-device interaction should always be borne in mind. Many drugs, including amiodarone and calcium channel blockers, especially verapamil, may increase the defibrillation threshold, sometimes dramatically. Antiarrhythmic drugs can also slow the ventricular tachycardia cycle length below the detection rate or increase shock frequency through proarrhythmic effects.

Some patients continue to experience frequent device discharges or have sustained ventricular tachycardia below the ICD rate cut off despite optimal antiarrhythmic drug treatment. Strickberger et al prospectively evaluated the utility of adjunctive radiofrequency catheter ablation of ventricular tachycardia in this situation. ${ }^{47}$ Ablation of the clinical arrhythmia was successful in $76 \%$ of 21 consecutive patients 
with coronary artery disease and significantly improved quality of life in these cases. Bundle branch re-entrant ventricular tachycardia is uncommon but uniquely amenable to catheter ablation and therefore should always be sought at electrophysiological testing in such patients. As previously mentioned, Wang et al found that supraventricular tachycardia was the cause of aborted sudden cardiac death in $13(4.5 \%)$ of 290 consecutive patients referred for electrophysiological evaluation. ${ }^{13}$ This uncommon clinical scenario is important to recognise as many of these patients can be cured by catheter ablation and cardioverter-defibrillator implantation is unnecessary.

Rarely, infranodal conduction system disease presents as a bradyarrhythmic cardiac arrest and permanent pacing, rather than defibrillator implantation, is indicated. ${ }^{48}$ Recent evidence suggests that isolated congenital complete heart block may not be as benign a condition as previously thought. ${ }^{49}$ In a large follow up study, there was a high incidence of Stokes-Adams attacks with considerable mortality from the first episode. ${ }^{49}$ Prophylactic permanent pacemaker implantation should therefore be considered even for adults who are asymptomatic.

In conclusion, the unsolved and enigmatic problem of sudden cardiac death continues to face patients with heart disease, health care providers, and society as well as regulatory bodies, funding agencies, and legislators. A close collaborative effort is required to meet the immense challenge posed by this condition.

1 Zipes DP, Wellens HJJ. Sudden cardiac death. Circulation 1998;98:2334-51.

2 Myerburg RJ, Kessler KM, Castellanos A. Sudden cardiac death: epidemiology, transient risk, and intervention assessment. Ann Intern Med 1993;119:1187-97.

3 Vreede-Swagemakers JJM, Gorgels APM, Dubois-Arbouw WI, et al. Out-of-hospital cardiac arrest in the 1990s: a population-based study in the Maastricht area on incidence,
characteristics and survival. 7 Am Coll Cardiol 1997;30: $1500-5$.

4 Siebels J, Cappato R, Ruppol R, et al. Preliminary results of the Cardiac Arrest Study Hamburg (CASH). Am $\mathcal{F}$ Cardio 1993;72:109-13F

5 Liberthson RR, Nagel EL, Hirschman JC, et al. Pathophysiologic observations in prehospital ventricular fibrillation ologic observations in prehospital ventricular fibril

6 Gilman JK, Naccarelli GV. Sudden cardiac death. Curr Probl Gardiol 1992;17:693-778.

7 Estes NAM. Sudden death in young athletes. $N$ Engl f Med 1995;333:380-1.

8 Echt DA, Liebson PR, Mitchell LB, et al. Mortality and morbidity in patients receiving encainide, flecainide or placebo. The Cardiac Arrhythmia Suppression Trial. N Engl f Med 1991;324:781-8.

9 Siscovick DS, Raghunathen TE, Psaty BM, et al. Diuretic therapy for hypertension and the risk of primary cardiac arrest. N Engl f Med 1994;330:1852-7.

10 Consensus statement of the joint steering committees of the UCARE and the IVF-US. Survivors of out-of-hospital cardiac arrest with apparently normal heart. Need for definition and standardized clinical evaluation. Circulation 1997; 95:265-72.

11 Eisenberg SJ, Scheinman MM, Dullet NK, et al. Sudden cardiac death and polymorphous ventricular tachycardia in patients with normal QT intervals and normal systolic cardiac function. Am 7 Cardiol 1995;75:687-92.

12 Roberts WC. Sudden cardiac death: a diversity of causes with focus on atherosclerotic coronary artery disease. $\mathrm{Am} \mathcal{F}$ Cardiol 1990;65:13-19B.

13 Wang Y, Scheinman MM, Chien WW, et al. Patients with supraventricular tachycardia presenting with aborted sudden death: incidence, mechanism and long-term follow-up. $\mathcal{f}$ Am Coll Cardiol 1991;18:1711-19.

14 Standards and guidelines for cardiopulmonary resuscitation (CPR) and emergency cardiac care (ECC), part IX: ensuring effectiveness of community-wide emergency cardiac care. fAMA 1992;268:2289-95.

15 Tunstall-Pedoe H, Bailey L, Chamberlain DA, et al. Survey of 3765 cardiopulmonary resuscitations in British hospitals of 3765 cardiopulmonary resuscitations in British hospitals
(the BRESUS study): methods and overall results. BMF (the BRESUS study)
$1992 ; 304: 1347-51$.
16 Bottiger BW, Grabner C, Bauer H, et al. Long term outcome after out-of-hospital cardiac arrest with physician staffed emergency medical services: the Utstein style applied to a midsized urban/suburban area. Heart 1999;82:674-9.

17 Vatterott PJ, Hammill SC, Bailey KR, et al. Late potentials on signal-averaged electrocardiograms and patency of the infarct-related artery in survivors of acute myocardial infarction. F Am Coll Cardiol 1991;17:330-7.

18 Longstreth WT, Inui TS, Cobb LA, et al. Neurological recovery after out-of-hospital cardiac arrest. Ann Intern Med 1983;98:588-92.

19 Multi-Society Task Force on PVS. Medical aspects of the persistent vegetative state (first of two parts). N Engl f Med 499-508.

20 Multi-Society Task Force on PVS. Medical aspects of the persistent vegetative state (second of two parts). $N$ Engl $\mathcal{F}$ Med 1994;330:1572-9.

21 Ritchie JL, Hallstrom AP, Troubaugh GB, et al. Out-ofhospital sudden coronary death: rest and exercise radionuclide left ventricular function in survivors. Am $\mathcal{f}$ Cardiol 1985;55:645-51.

22 McKenna WJ, Thiene G, Nava A, et al. Diagnosis of arrhythmogenic right ventricular dysplasia/cardiomyopathy. Br Heart F 1994:71:215-18.

23 Arteaga WJ, Windle JR. The quality of life of patients with life-threatening arrhythmias. Arch Intern Med 1995;155: 2086-91.

24 Antiplatelet Trialists' Collaboration. Collaborative overview of randomized trials of antiplatelet therapy-I: prevention of death, myocardial infarction, and stroke by prolonged antiplatelet therapy in various categories of patients. $B M F$ 1994;308:81-106.

25 Scandinavian Simvastatin Survival Study Group. Randomized trial of cholesterol lowering in 4444 patients with coronary heart disease: the Scandinavian Simvastatin Survival Study (4S). Lancet 1994;334:1383-9.

26 CONSENSUS Trial Study Group. Effects of enalapril on mortality in severe congestive heart failure. Results of the Cooperative North Scandinavian Enalapril Survival Study (CONSENSUS). N Engl f Med 1987;316:1429-35.

27 Domanski MJ, Exner DV, Borkowf CB, et al. Effect of angiotensin converting enzyme inhibition on sudden cardiac death in patients following acute myocardial infarction. A meta-analysis of randomized clinical trials. $7 \mathrm{Am}$ Coll Cardiol 1999;33:598-604.

28 Pitt B, Segal R, Martinez FA, et al. Randomized trial of losartan versus captopril in patients over 65 with heart failure
(Evaluation of Losartan in the Elderly Study, ELITE). Lancet 1997;349:747-52.

29 Pitt B, Zannad F, Remme WJ, et al. The effect of spironolactone on morbidity and mortality in patients with severe heart failure. N Engl f Med 1999;341:709-17.

30 Kendall MJ, Lynch KP, Hjalmarson A, et al. Beta-blockers and sudden cardiac death. Ann Intern Med 1995;123:35867.

31 Packer M, Bristow MR, Cohn JN, et al. The effect of carvedilol on morbidity and mortality in patients with chronic heart failure. N Engl F Med 1996;334:1349-55.

32 MERIT-HF Study Group. Effect of metoprolol CR/XL in chronic heart failure: Metoprolol CR/XL Randomized chronic heart failure: Metoprolol CR/XL Randomized
Intervention Trial in Congestive Heart Failure (MERITHF). Lancet 1999;353:2001-7.

33 CIBIS-II Investigators and Committees. The Cardiac Insufficiency Bisoprolol Study II (CIBIS-II): a randomized trial. Lancet 1999;353:9-13.

34 Holmes DR, Davis KB, Mock MB, et al. The effect of medical and surgical treatment on subsequent sudden cardiac death in patients with coronary artery disease: a report from the Coronary Artery Surgery Study. Circulation 1986;73: 1254-63.

35 Every NR, Fahrenbruch CE, Hallstrom AP, et al. Influence of coronary bypass surgery on subsequent outcome of patients resuscitated from out of hospital cardiac arrest. $\mathcal{F}$ Am Coll Cardiol 1992;19:1435-9.

36 Antiarrhythmics Versus Implantable Defibrillators (AVID) Investigators. A comparison of antiarrhythmic drug therapy with implantable defibrillators in patients resuscitated from near-fatal ventricular arrhythmias. $N$ Engl f Med 1997;337: 1576-83.

37 Ferguson JJ. Meeting highlights. 47th annual scientific sessions of the American College of Cardiology. Circulation 1998;97:2377-81.

38 Connolly SJ, Gent M, Roberts RS, et al. Canadian Implantable Defibrillator Study (CIDS). A randomized trial of the implantable cardioverter defibrillator against amiodarone. Circulation 2000;101:1297-302.

39 Gregoratos G, Cheitlin MD, Freedman RA, et al. ACC/ AHA guidelines for implantation of cardiac pacemakers and 209.

40 Anderson JL, Hallstrom AP, Epstein AE, et al. Design and results of the Antiarrhythmics vs Implantable Defibrillators (AVID) registry. Circulation 1999;99:1692-9.

41 Ruppel R, Schluter CA, Boczor S, et al. Ventricular tachycardia during follow-up in patients resuscitated from ventricular fibrillation: experience from stored electrograms of implantable cardioverter-defibrillators. $7 \mathrm{Am}$ Coll Cardiol 1998;32:1724-30.

42 Epstein AE, Miles WM, Benditt DG, et al. Personal and public safety issues related to arrhythmias that may affect consciousness: implications for regulation and physician recommendations. Circulation 1996;94:1147-66. 
43 CASCADE Investigators. Randomized antiarrhythmic drug therapy in survivors of cardiac arrest (the CASCADE study). Am 7 Cardiol $1993 ; 72: 280-7$.

44 Sim I, McDonald KM, Lavori PW, et al. Quantitative overview of randomized trials of amiodarone to prevent sudden cardiac death. Circulation 1997;96:2823-9.

45 Credner SC, Klingenheben T, Mauss O, et al. Electrical storm in patients with transvenous implantable cardioverterdefibrillators. Incidence, management and prognostic implications. F Am Coll Cardiol 1998;32:1909-15.

46 Pacifico A, Hohnloser SH, Williams JH, et al. Prevention of implantable defibrillator shocks by treatment with sotalol. $N$ Engl f Med 1999;340:1855-62.
47 Strickberger SA, Man KC, Daoud EG, et al. A prospective evaluation of catheter ablation of ventricular tachycardia as adjuvant therapy in patients with coronary artery disease and an implantable cardioverter defibrillator. Circulation 1997;96:1525-31.

48 Scheinman MM, Peters RW, Sauve MJ, et al. Value of the $\mathrm{H}-\mathrm{O}$ interval in patients with bundle branch block and the role of prophylactic permanent pacing. $A$. $\mathcal{F}$ Cardiol 1982.50:1316-22.

49 Michaelsson M, Jonzon A, Riesenfeld T. Isolated congenital complete atrioventricular block in adult life. A prospective study. Circulation 1995;92:442-9.

\section{Medical Anniversary}

\section{Sir George Pickering, 26 June 1904}

George Pickering (1904-80) was born in Whalton, Northumberland, son of a schoolteacher with strong farming traditions. He was educated at Dulwich, Pembroke College, Cambridge, and St Thomas' where he qualified in 1928. He became professor of medicine at St Mary's in 1939 and Oxford in 1956. His research provided the basis of the epidemiology of blood pressure in populations, and he brought numeracy into clinical thinking. He was a devoted historian of medicine and helped to found the Osler Club of London (1928). He died on 3 September 1980.-D G fames 